\title{
Mechanical and Thermal Properties of a Diglycidyl Ether of Bisphenol-A (DGEBA)-4,4'-Diaminodiphenyl Sulfone (DDS) System Cured under Hydrostatic Pressure
}

\author{
Jong Keun LeE and K. D. PAE* \\ Department of Polymer Science and Engineering, \\ Kumoh National University of Technology, \\ Kumi City, KyungBuk 730-701, Korea \\ *High Pressure Materials Research Laboratory and Department of \\ Mechanical and Aerospace Engineering, Rutgers University, \\ Piscataway, NJ 08855-0909, U.S.A.
}

(Received October 25, 1993)

\begin{abstract}
Samples of a diglycidyl ether of bisphenol-A (DGEBA)-4,4'-diaminodiphenyl sulfone (DDS) system have been cured under various hydrostatic pressures from atmospheric to $162 \mathrm{MPa}$ of $\mathrm{N}_{2}$ gas at $150^{\circ} \mathrm{C}$ and characterized by means of dynamic mechanical analysis (DMA) and differential scanning calorimetry (DSC). The glass transition temperature $\left(T_{\mathrm{g}}\right)$ of the pressure-cured samples was found to increase and then decrease with increasing cure pressure. The $T_{\mathrm{g}}$, determined by DMA, varied from $184^{\circ} \mathrm{C}$ for samples cured at atmospheric pressure to $205^{\circ} \mathrm{C}$ for samples cured at $35 \mathrm{MPa}$, and then to $181^{\circ} \mathrm{C}$ for samples cured at $162 \mathrm{MPa}$. The $T_{\mathrm{g}}$ of the pressure-cured samples was also determined by DSC and found to undergo the same trend of that obtained by DMA but at slightly lower temperatures. The storage modulus in glassy state of samples cured at different pressures varies only slightly, but the equilibrium modulus obtained from the rubbery plateau region increased rapidly and reached the maximum at the cure pressure of $35 \mathrm{MPa}$ and then decreased with increasing cure pressure.
\end{abstract}

KEY WORDS Hydrostatic Pressure / Dynamic Mechanical Properties /

Glass Transition Temperature / Epoxy / Amine /

Epoxy resins are superior in adhesion, heat and corrosion resistance, and mechanical and electrical properties than other thermosetting resins. Consequently, they are widely used as adhesives, coating materials, building materials, substrates for electronic chips, matrices for composite materials, etc. For proper use of the materials on these applications, it is important and desirable to understand the curing process and to achieve optimum properties.

Curing process of epoxy resin-hardener systems at various temperatures have been extensively studied by many workers. ${ }^{1-7}$ For further understanding of the curing process, hydrostatic pressure has recently been introduced as a parameter like temperature by
Lee and Pae. ${ }^{8,9}$ They employed torsion pendulum which was built into a high pressure vessel to monitor the curing process. ${ }^{10}$ One of the results obtained by Lee and Pae, shown in Figure 1, indicates that many changes do occur on log decrement vs. cure time curves due to applied hydrostatic pressure. These curves exhibit two macroscopic phenomena known as gelation and vitrification. The time position of these two peaks shifts toward the shorter time scale with increasing pressure. The amount of the shifts of the two peaks is different; in fact, the vitrification peak shifts three times faster than the gelation peak. ${ }^{9}$ As a result, the two peaks would merge together at pressure of around $160 \mathrm{MPa}$. In addition, the size of the 
two peaks undergoes changes as well. The size of the vitrification peaks decreases while that of the gelation peaks increases.

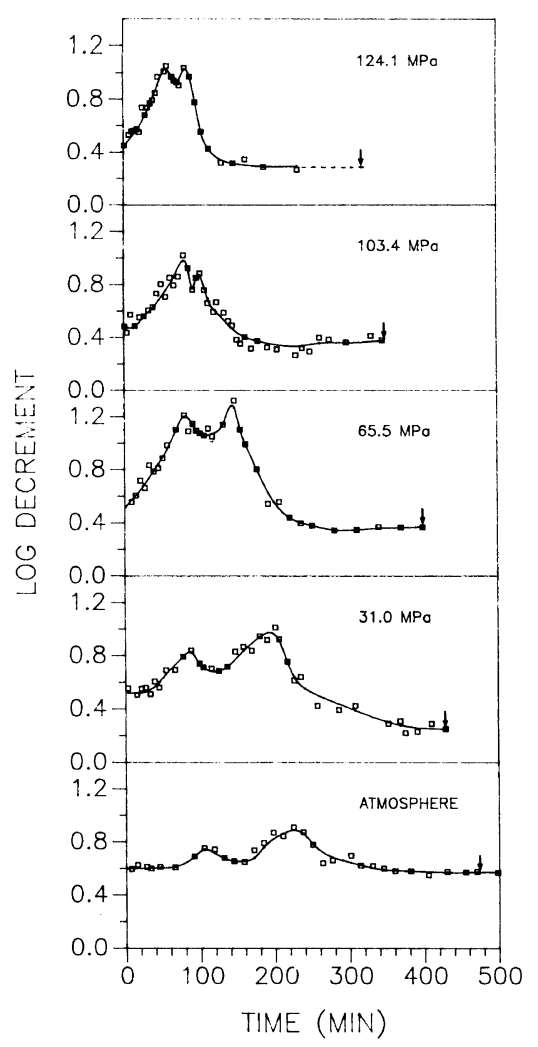

Figure 1. Variation of logarithmic decrement with cure time at various cure pressures at $150^{\circ} \mathrm{C} .{ }^{9}$ The extent of cure times is marked by an arrow.
These observed phenomena do indicate the possibility of inducing different mechanical and thermal properties in the pressure-cured samples. These properties were investigated and reported in this paper. Nakamae et al. ${ }^{11}$ and Beloshenko et al. ${ }^{12}$ have also investigated pressure effects on these properties of epoxy systems.

\section{MATERIALS AND METHODS}

\section{Materials}

The materials used in this study were diglycidyl ether of bisphenol-A (DGEBA, Shell Chemical Co., Epon 828) epoxy resin and 4,4'-diaminodiphenyl sulfone (DDS, Aldrich Chemical Co.) hardener. The chemical formulae of the materials are represented in Figure 2. The Epon resin 828 is a mixture of molecules composed of about $85 \%$ of $n=0$ molecules and about $15 \%$ of the $n=1$ species. The epoxide equivalent weight of the Epon 828 is 185$192 \mathrm{~g} \mathrm{~mol}^{-1}$. This resin has two glycidyl functional groups, one at each end, which are highly strained. The curing agent DDS has four amine hydrogens, and its molecular weight is $248.3 \mathrm{~g} \mathrm{~mol}^{-1}$.

\section{Sample Preparation}

In order to make samples for DMA, a flat dumbbell-shaped mold was constructed of
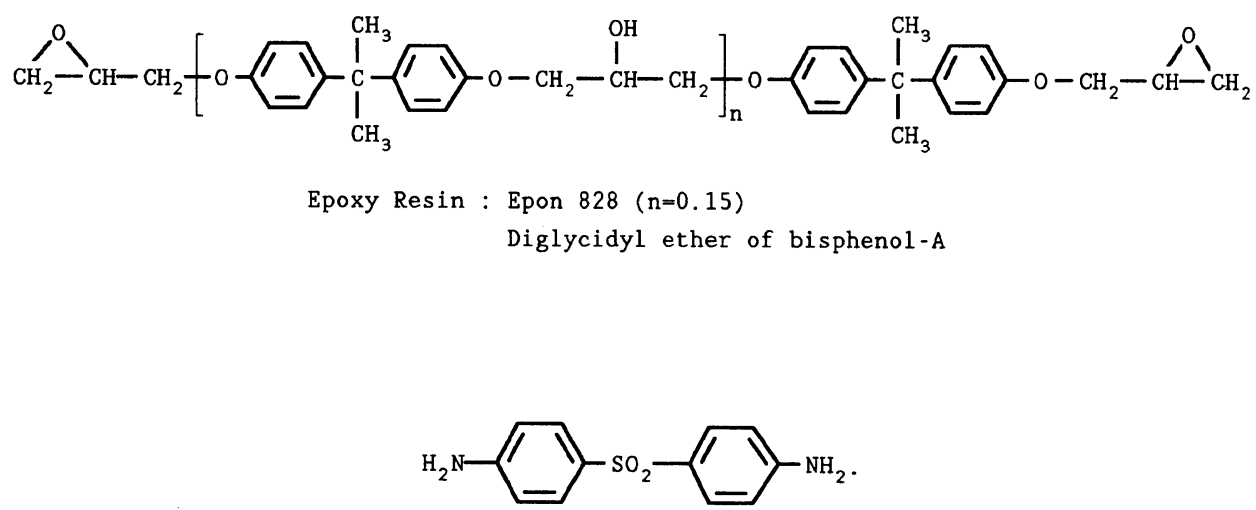

Hardener : 4,4'-Diaminodiphenyl sulfone

Figure 2. Chemical formulae of DGEBA and DDS. 
brass. The mold was epoxied onto a glass plate after the inner surface of the mold was covered with aluminum foil for easy removal of the cured samples.

A beaker containing the epoxy resin was, at first, placed in a silicon oil bath which was preheated to $135^{\circ} \mathrm{C}$. When the resin appeared to be melted without bubbles, the curing agent DDS measured to a stoichiometric amount was put into the beaker and stirred mechanically for about $35 \mathrm{~min}$ until the two were completely blended. The blended melt was then poured into the mold and cooled to room temperature. The mold, which contained the melt, was inserted into the pressure vessel, pressure increased to a desired level, temperature raised to $150^{\circ} \mathrm{C}$, and the melt was allowed to cure for a predetermined period of time indicated in Figure 1. After the curing under pressure, temperature was lowered to room temperature, maintaining the pressure constant. The pressure was then lowered to atmospheric pressure and the mold was removed from the vessel.

Temperature of the sample in the mold was monitored by a thermocouple (ChromelAlumel type) the tip of which was located at the center of the mold. The pressure medium for this study was dry nitrogen gas. The gage section of the cured sample pressed out of the mold was $22.5 \mathrm{~mm}$ long, $10 \mathrm{~mm}$ wide, and $4.5 \mathrm{~mm}$ thick. The sample was sliced to the thickness of $0.33-0.38 \mathrm{~mm}$ by a slow speed diamond saw. Postcuring of the sliced sample was carried out at $180^{\circ} \mathrm{C}$ for three hours and then $230^{\circ} \mathrm{C}$ for two hours.

The details of the pressure vessel, high pressure gas pumping system, and temperature controller are described in ref 10 .

\section{Experimental Procedure}

Dynamic Mechanical Analysis (DMA). DMA was made by Rheometrics Dynamic Spectrometer (RDS-7700, Rheometrics Co.). The instrument controlled the temperature automatically, including thermal soak time of one minute to stabilize the temperature prior to conducting test. The tests were made in a tension-compression mode at $1 \mathrm{~Hz}$ in nitrogen gas atmosphere. Dynamic mechanical spectra of the pressure-cured samples were generated at temperatures from room temperature to $250^{\circ} \mathrm{C}$; at intervals of $25^{\circ} \mathrm{C}$ in the glassy state, $10^{\circ} \mathrm{C}$ in the rubbery state, and $5^{\circ} \mathrm{C}$ in the transition region. The each temperature increment took about three minutes.

Differential Scanning Calorimetry (DSC). DSC (Du Pont 910) was employed to determine $T_{\mathrm{g}}$ and the exothermic heat of reaction for cured samples. Samples were heated at $10^{\circ} \mathrm{C}$ $\min ^{-1}$ under continuous flow of nitrogen gas. A sliced sample for DMA was cut into small pieces weighing approximately $10-15 \mathrm{mg}$.

An endothermic peak appeared during the first scanning up through $T_{\mathrm{g}}$. In order to eliminate the peak and obtain a stepwise transition, the samples were heated to just above the endothermic peak, followed by quenching to room temperature at $30^{\circ} \mathrm{C} \mathrm{min}^{-1}$ in the DSC. Then the samples were reheated to $350^{\circ} \mathrm{C}$.

\section{RESULTS AND DISCUSSION}

Dynamic mechanical spectra, storage modulus and $\tan \delta$ vs. temperature curves, of samples cured at $150^{\circ} \mathrm{C}$ under various pressures are shown in Figures 3 and 4 . The storage modulus in the glassy state varies little with cure pressure. The equilibrium modulus at the rubbery plateau, however, varies with cure pressure. The entire transition region on the storage modulus shifts to higher temperatures with increasing cure pressure up to about $35 \mathrm{MPa}$ as shown in Figure 3 and then shift down to lower temperatures with cure pressure to $162 \mathrm{MPa}$ as shown in Figure 4. The peak temperature on $\tan \delta$ curves follows the trend set by the transition region of the storage modulus.

Figure 5 shows DSC scans for uncured and cured samples at various pressures indicated. The scan for the uncured shows a single broad 


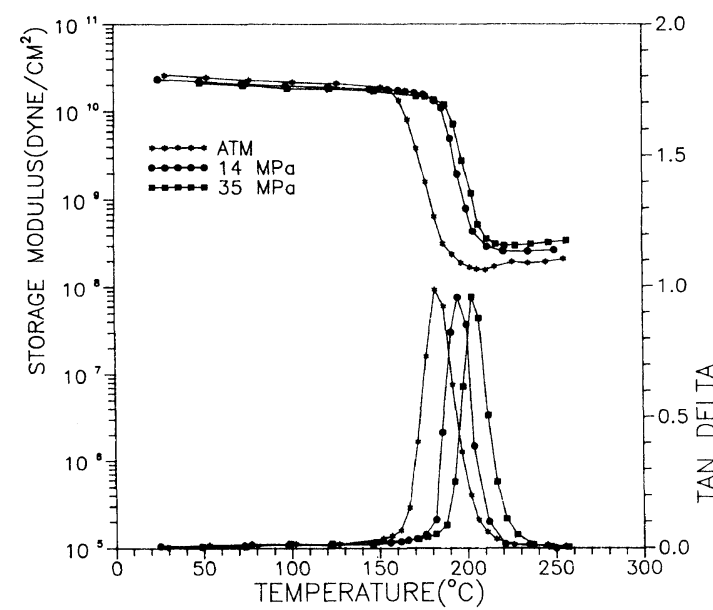

Figure 3. Dynamic mechanical spectra of samples cured at $150^{\circ} \mathrm{C}$ and at various pressures indicated.

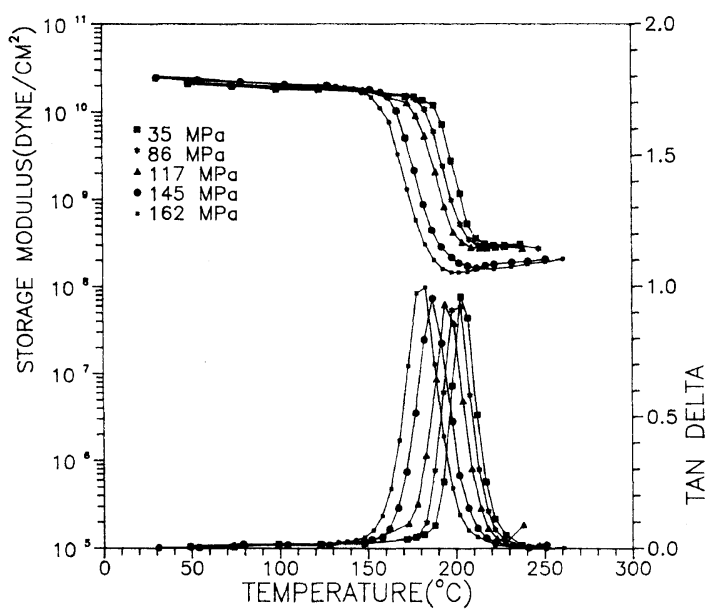

Figure 4. Dynamic mechanical spectra of samples cured at $150^{\circ} \mathrm{C}$ and at various pressures indicated.

exothermic peak. The scans for the cured samples exhibit stepwise transitions and exothermic peaks, which respectively correspond to $T_{\mathrm{g}}$ and the residual heat of cure reaction.

$T_{\mathrm{g}}$ of the cured samples was determined from the peak location of $\tan \delta$ vs. temperature curves of Figures 3 and 4, and plotted in Figure 6 as a function of cure pressure. $T_{\mathrm{g}}$ of the sample cured at atmospheric pressure is located at $184^{\circ} \mathrm{C} . T_{\mathrm{g}}$ increases to a maximum value of $205^{\circ} \mathrm{C}$ for the sample cured at $35 \mathrm{MPa}$ and then decreases with increasing cure pressure. The $T_{\mathrm{g}}$

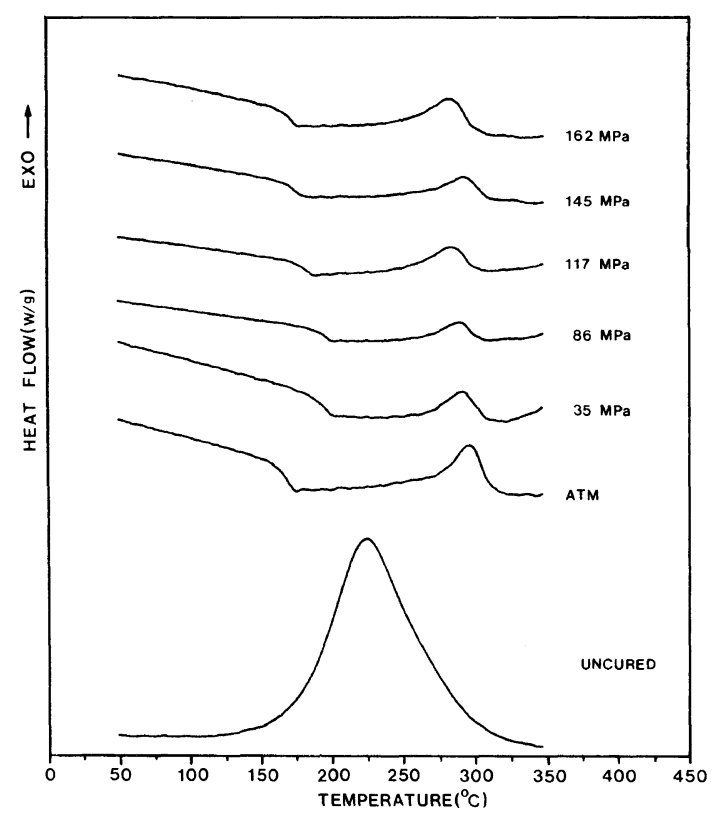

Figure 5. DSC scans of uncured and cured samples at $150^{\circ} \mathrm{C}$ and at various pressures indicated.

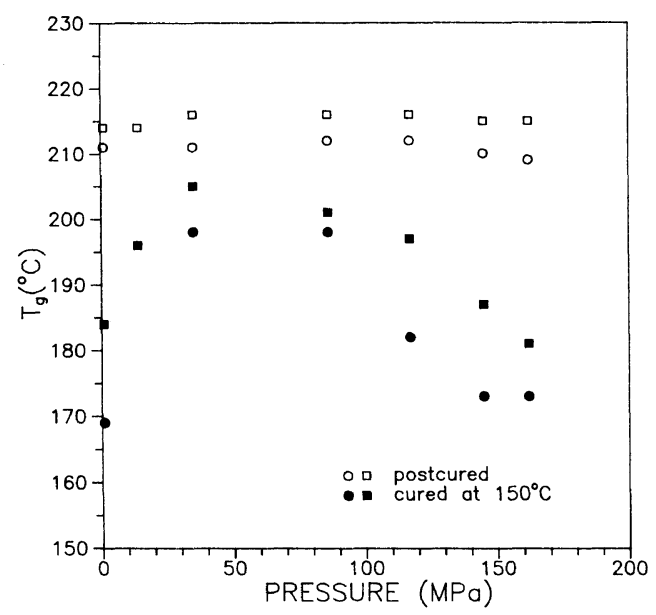

Figure 6. The glass transition temperature of samples cured at $150^{\circ} \mathrm{C}$ and at various pressures, and of the same samples postcured, obtained by DMA $(\square, \square)$ and by DSC $(\odot, \bigcirc)$.

of the postcured samples is nearly constant value of $215 \pm 1{ }^{\circ} \mathrm{C}$ regardless of cure pressure. The effect of the cure pressure on $T_{\mathrm{g}}$ is completely erased once the samples are postcured. Figure 6 also contains $T_{\mathrm{g}}$ obtained by DSC. 
The $T_{\mathrm{g}}$ by DSC undergoes the same trend as that by DMA but at slightly lower temperatures.

The cure reaction is known to be kinetically controlled in the earlier stage of cure and become diffusion controlled after vitrification. ${ }^{1,13,14}$ In the kinetically controlled region, the effect of pressure on the reaction can be explained by a transition theory, ${ }^{15}$ described by

$$
\left.\frac{\mathrm{d} \ln k}{\mathrm{~d} p}\right|_{T}=-\frac{\Delta V^{\prime}}{R T}
$$

where $k$ is a rate constant, $\Delta V^{\prime}$ the activation volume, $R$ the gas constant, and $T$ the absolute temperature. The activation volume, $\Delta V^{\prime}=$ $\left(V^{\prime}-V_{\mathrm{R}}\right)$, is the volume difference between a transition state $\left(V^{\prime}\right)$ and a reactant $\left(V_{\mathbf{R}}\right)$. Equation 1 describes that the rate constant $(k)$ increases with pressure when $\Delta V^{\prime}$ is negative. The activation volume for over 700 reactions has been listed by Asano and le Noble. ${ }^{16}$ Although the absolute value of $\Delta V^{\prime}$ for a DGEBA-DDS system is not known, hydrostatic pressure is reported to accelerate the cure process of the system. ${ }^{9}$ However, in the diffusion controlled region, the cure reaction would be retarded because functional groups need to diffuse to react, and pressure makes the functional groups more difficult to diffuse. It appears then that the increase of the extent of reaction at lower pressures would be expected due to the acceleration of cure reaction in the kinetically controlled region.

At higher pressures, in addition to the increased difficulty in diffusion, the following effects of pressure may also induce the decrease of the extent of reaction. At first, both gelation and vitrification peaks shift to a shorter time scale. Secondly, the amount of the shift is greater for vitrification than gelation, causing the two phenomena to merge together and then overlap. When the gelation and vitrification peaks overlap, a certain number of molecules may vitrify while others gel. The number of molecules under diffusion controlled is greater than that under kinetically controlled. Thirdly, the area ratio of the two $\left(A_{\mathrm{vit}} / A_{\mathrm{gel}}\right)$ reduces. Figure 1 demonstrates all three phenomena in a form of gelation and vitrification peaks. Therefore, the amount of the reaction that occurs during and after vitrification is expected to be reduced.

A quantitative measure of the extent of reaction may normally be obtained by determining the heat of reaction. ${ }^{17}$ However, we encountered a great difficulty in correctly measuring the area under the exothermic peaks of DSC scans of the pressure-cured samples because the baseline of the scan changed continuously. The obtained data are unreliable and therefore we refer the extent of cure data obtained by FTIR which was reported in ref 9 .

From the equilibrium modulus determined from the rubbery plateau region of the storage modulus vs. temperature curves in Figures 3 and 4 , the average molecular weight between crosslinks $\left(M_{\mathrm{c}}\right)$, can be determined by the following equation, ${ }^{18}$

$$
G_{\mathrm{c}}=\frac{\phi \rho R T}{M_{\mathrm{c}}}
$$

where $\phi$ is known as a front factor and $\rho$ is

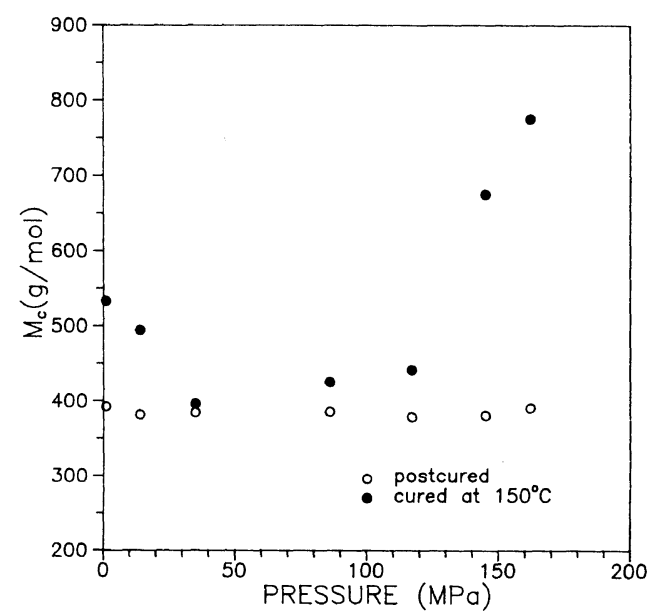

Figure 7. Variation of molecular weight between crosslinks of samples cured at $150^{\circ} \mathrm{C}$ with cure pressure and of the same samples postcured. 
Table I. Values of the glass transition temperature and molecular weight between crosslinks of samples cured at $150^{\circ} \mathrm{C}$ under various pressures and of same samples postcured ${ }^{\mathrm{a}}$

\begin{tabular}{|c|c|c|c|}
\hline Pressure & \multirow{2}{*}{$\begin{array}{c}T_{\mathrm{g}} /{ }^{\circ} \mathrm{C} \\
\text { from DMA }\end{array}$} & \multirow{2}{*}{$\begin{array}{c}T_{\mathrm{g}} /{ }^{\circ} \mathrm{C} \\
\text { from DSC }\end{array}$} & \multirow{2}{*}{$\frac{M_{\mathrm{c}}}{\mathrm{g} \mathrm{mol}^{-1}}$} \\
\hline $\mathrm{MPa}$ & & & \\
\hline atm & $184(214)$ & $169(211)$ & $533(392)$ \\
\hline 14 & $196(214)$ & n.a. & $494(381)$ \\
\hline 35 & $205(216)$ & $198(211)$ & $396(384)$ \\
\hline 86 & $201(216)$ & $198(212)$ & $425(385)$ \\
\hline 117 & $197(216)$ & $182(212)$ & $441(378)$ \\
\hline 145 & $187(215)$ & $173(210)$ & $675(380)$ \\
\hline 162 & $181(215)$ & $173(209)$ & 775 (390) \\
\hline
\end{tabular}

a ( ), postcured. n.a., not available.

the density of a material. In calculation of $M_{\mathrm{c}}$, using eq 2 , the equilibrium modulus at $T_{\mathrm{g}}+40^{\circ} \mathrm{C}$, the front factor and the density taken to be one, as usual, were used. The value of $M_{\mathrm{c}}$ thus obtained is shown in Figure 7. It decreases first from $533 \mathrm{~g} \mathrm{~mol}^{-1}$ for the atmosphere-cured sample to $396 \mathrm{~g} \mathrm{~mol}^{-1}$ for a $35 \mathrm{MPa}$-cured and then increases thereafter to $775 \mathrm{~g} \mathrm{~mol}^{-1}$ for a $162 \mathrm{MPa}$-cured. The $M_{\mathrm{c}}$ value for our postcured samples is found to be about $385 \mathrm{~g} \mathrm{~mol}^{-1}$. The theoretical value of $M_{\mathrm{c}}$ for a fully-cured sample for a DGEBA-DDS system is $336 \mathrm{~g} \mathrm{~mol}^{-1}$. The values of $M_{\mathrm{c}}$ of our samples are listed in Table I.

\section{CONCLUSIONS}

Hydrostatic pressure influences the curing reaction and can be a controlling factor like temperature. The effects of pressure on gelation and vitrification are different which produces various values of $T_{\mathrm{g}}$ and $M_{\mathrm{c}}$. The $T_{\mathrm{g}}$ of the pressure-cured samples was found to increase and then decrease with increasing cure pressure. The $T_{\mathrm{g}}$, determined by DMA, varied from $184^{\circ} \mathrm{C}$ for samples cured at atmospheric pressure to $205^{\circ} \mathrm{C}$ for samples cured at 35 $\mathrm{MPa}$, and then to $181^{\circ} \mathrm{C}$ for samples cured at $162 \mathrm{MPa}$. After postcuring all the samples under atmospheric pressure, $T_{\mathrm{g}} \mathrm{s}$ were found to be about $215^{\circ} \mathrm{C}$. The $M_{\mathrm{c}}$ estimated from the rubbery plateau modulus was $533 \mathrm{~g} \mathrm{~mol}^{-1}$ for the atmospheric-cured sample, and 396 $\mathrm{g} \mathrm{mol}^{-1}$ for the $35 \mathrm{MPa}$-cured one. The $M_{\mathrm{c}}$ increased to $775 \mathrm{~g} \mathrm{~mol}^{-1}$ for the $162 \mathrm{MPa}-$ cured sample. After postcuring, the $M_{\mathrm{c}}$ reduced to about $385 \mathrm{~g} \mathrm{~mol}^{-1}$. The storage modulus in glassy state of samples cured at different pressures varies only slightly, but the equilibrium modulus obtained from the rubbery plateau region increased rapidly and reached the maximum at the cure pressure of $35 \mathrm{MPa}$ and then decreased with increasing cure pressures.

By a proper control of a combination of pressure and temperature, it should be possible to produce high $T_{\mathrm{g}}$ and consequently low $M_{\mathrm{c}}$ values of cured epoxy/hardener systems.

\section{REFERENCES}

1. J. B. Enns and J. K. Gillham, J. Appl. Polym. Sci., 28, 2567 (1983).

2. N. S. Schneider, J. F. Sprouse, G. L. Hagnauer, and J. K. Gillham, Polym. Eng. Sci., 19, 304 (1979).

3. D. Harran and A. Laudouard, J. Appl. Polym. Sci., 32, 6043 (1986).

4. D. Serrano and D. Harran, Polym. Eng. Sci., 29, 531 (1989).

5. C. Y-C. Lee and I. J. Goldfarb, Polym. Eng. Sci., 21, 390 (1981).

6. M. J. Doyle, A. F. Lewis, and H. Li, Polym. Eng. Sci., 19, 687 (1979).

7. C. M. Tung and P. J. Dynes, J. Appl. Polym. Sci., 27, 569 (1982).

8. J. K. Lee and K. D. Pae, J. Polym. Sci., Polym. Lett., 28, 323 (1990).

9. J. K. Lee and K. D. Pae, J. Macromol. Sci.-Phys., B32(1), 79 (1993).

10. J. K. Lee and K. D. Pae, Korean J. Mater. Res., 3, 395 (1993).

11. K. Nakamae, T. Nishino, $X$. AiRu, and $K$. Takatshuka, Polym. J., 23, 1157 (1991).

12. V. A. Beloshenko, M. K. Pakter, B. I. Beresnev, T. P. Zaika, V. G. Slobodina, and V. M. Shepel, Mechanics of Composite Materials, 26, 149 (1990).

13. G. Wisanrakkit and J. K. Gillham, J. Coat. Tech., 62, 35 (1990).

14. I. Mita and K. Horie, J. Macromol. Sci.-Rev. Macromol. Chem. Phys., C27(1), 91 (1987).

15. S. Glasstone, K. J. Laidler, and H. Eyring, "The Theory of Rate Process," McGraw-Hill, New York, 


\section{Properties of a Pressure Cured Epoxy}

N.Y., 1941

16. W. J. le Noble, Ed., "Organic High Pressure Chemistry," Elsevier, Amsterdam, Netherlands, 1988, Chapter 1.

17. R. B. Prime, in "Thermal Characterization of
Polymeric Materials," E. A. Turi, Ed., Academic Press, New York, N.Y., 1981.

18. A. V. Tobolsky, "Properties and Structure of Polymers," Wiley, New York, N.Y., 1960. 